\title{
Occurrence and Morphology of Martensite in $\beta$-Cu-Zn Alloys with Minor Al Additions
}

\author{
T. KAADEN, P. WUTZLER, and S. LIPPMANN
}

The limits of occurrence and the morphology of martensite in $\mathrm{Cu}-\mathrm{Zn}-\mathrm{Al}$ alloys with 30 to $50 \mathrm{wt}$ pct $\mathrm{Zn}$ and $\leq 1.5$ wt pet $\mathrm{Al}$ have been investigated. In samples with concentration gradients, various conditions for the competition between martensitic and massive transformation have been observed. Microstructural details of martensite were obtained by combining vibration polishing, chemical or plasma etching and polarized light, backscattered electron channeling contrast or electron backscatter diffraction analysis. Depending on the cooling rate, martensite undergoes a morphological change from self-accommodating thin plates to lenticular shaped plates, which is documented for the first time in $\mathrm{Cu}$-based alloys. The number of martensite twins in the investigated compositional range was found to be significantly smaller than that in commercial $\mathrm{Cu}-\mathrm{Zn}-\mathrm{Al}$ alloys that are used as shape memory alloys.

https://doi.org/10.1007/s11661-020-05769-2

(c) The Author(s) 2020

\section{INTRODUCTION}

IN Cu-Zn(-Al) alloys, two different types of concentration invariant phase transformations are observed at high quenching rates, particularly massive and martensitic transformation. The mechanisms of the two solid-state transformation are known to be significantly different.

During massive transformation in the system $\mathrm{Cu}-\mathrm{Zn}$, bcc $\left(\beta\right.$ or $\left.\beta^{\prime}\right)$ transforms to fcc, which may be stable or metastable at low temperatures. ${ }^{[1-4]}$ The morphology of the product phase is described as "blocky" or "massive," where the latter expression is used as designation of the type of transformation. Typical transformation rates in $\mathrm{Cu}-\mathrm{Zn}$-based alloys are in the order of $10^{-2} \mathrm{~m} /$ $\mathrm{S}^{[2]}$ and are not accompanied by long-range diffusion, but only by diffusion in the interfacial region.

The martensitic transformation is diffusionless and characterized by a cooperative movement of atoms across an interface, transferring a parent into a product crystal structure while retaining atomic neighborhoods. ${ }^{[5,6]}$ The growth rates are in the order of $10^{3} \mathrm{~m} /$ $\mathrm{s}^{[7]}$ and thus among the highest rates observed in solids. The martensite morphology in $\mathrm{Cu}-\mathrm{Zn}-\mathrm{Al}$ alloys was observed be only plate martensite ${ }^{[8-11]}$ which represents a distinct difference to other alloy systems in which several different types of martensite morphologies are

T. KAADEN, P. WUTZLER, and S. LIPPMANN are with the Friedrich Schiller University Jena, Otto Schott Institute of Materials Research, 07743 Jena, Germany. Contact e-mail: stephanie.lippmann@uni-jena.de

Manuscript submitted August 21, 2019.

Article published online April 22, 2020 reported depending on cooling rate or alloy composition (see e.g. martensite morphologies in the Fe-C system in Reference 12). The martensite plates in $\mathrm{Cu}-\mathrm{Zn}-\mathrm{Al}$ show self-accommodating behavior by forming type II twins $^{[8-11]}$ (which is necessary for the application as shape memory alloys ${ }^{[13]}$.

The type of concentration invariant transformation that occurs during quenching strongly depends on the solute concentration that determines the martensite start temperature ${ }^{[14]}$ In binary $\mathrm{Cu}-\mathrm{Zn}$ alloys, the competition of martensitic and massive transformation can hardly be observed, since the martensite start temperature is $-50{ }^{\circ} \mathrm{C} .{ }^{[15]}$ Ternary alloys such as $\mathrm{Cu}-38 \mathrm{Zn}-0.5 \mathrm{Al}$ ("CC767S," all concentrations in wt pet) and Cu-37Zn-1Al ("CC766S") with $\mathrm{Al}$ concentrations below $1.8 \mathrm{wt}$ pct are frequently used in industrial chill castings and show both types of transformation. At higher solute concentrations (18 to $26 \mathrm{wt}$ pet $\mathrm{Zn}$ and 3 to $5 \mathrm{wt}$ pct $\mathrm{Al}^{[4]}$ ), the formation of martensite always precedes the massive transformation. Alloys in this composition range are typically used as shape memory alloys and often employed as low cost alternative to $\mathrm{Ni}-\mathrm{Ti}^{[16]}{ }^{[16 . g}$., as actuators. ${ }^{[17]}$

Until present, the transition from one type of transformation to the other one is not well understood, and suitable concentration ranges and cooling rates are not known precisely. One objective of this work is to experimentally identify the parameters for the transition, using samples with concentration gradients and exposing them to varying cooling rates and different quenching media. In addition, the martensite morphology of $\mathrm{Cu}-\mathrm{Zn}-\mathrm{Al}$ alloys with low $\mathrm{Al}$ concentration is studied depending on the cooling rate and the potential application as shape memory alloy is discussed. 


\section{EXPERIMENTAL}

The martensitic transformation in $\mathrm{Cu}-\mathrm{Zn}-\mathrm{Al}$ alloys is limited to a concentration range in which, for a given composition, both $\alpha$ and $\beta$ (or $\beta^{\prime}$ ) are stable at different temperatures. With the purpose of identifying suitable compositions efficiently, diffusion couples that cover a range of concentrations were employed. Alloys with the nominal composition (in wt pct) of $\mathrm{Cu}-30 \mathrm{Zn}-\mathrm{X} \mathrm{Al}$ and $\mathrm{Cu}-50 \mathrm{Zn}-\mathrm{X} \mathrm{Al}(X=0.5,0.75$ or 1.5$)$ were melted in a quartz glass tube (inner diameter: $10 \mathrm{~mm}$, wall thickness: $1.5 \mathrm{~mm}$ ) using a high frequency induction furnace (coil length: $70 \mathrm{~mm}$, inner diameter: $65 \mathrm{~mm}, 7$ windings). Before the melting process, the glass tubes were evacuated $(<100 \mathrm{~Pa})$, filled with inert gas (Argon $5.0,30 \mathrm{kPa})$ to prevent oxidation and sealed. A homogenous solute distribution was achieved by forced convection during a holding time of 10 minutes at $50 \mathrm{~K}$ above the liquidus temperature and a heat treatment after solidification at $560^{\circ} \mathrm{C}$ for 24 hours. After machining to cylinders (diameter: $7.8 \mathrm{~mm}$, height: $5 \mathrm{~mm}$ ), the samples were transferred into a glove box with oxygen free atmosphere $(<2$ $\mathrm{ppm})$. Surface oxides were removed manually using $\mathrm{SiC}$ grinding paper (4000 grit). Pairs of cylinders with identical Al, but different $\mathrm{Zn}$ concentration were then placed in a capsule for diffusion welding (for details about the diffusion capsule, see Reference 18). For diffusion welding a temperature of $800{ }^{\circ} \mathrm{C}$, a holding time of 6 hours and a joining pressure of $2 \mathrm{MPa}$ were chosen. After welding, the joined cylinders were cut to $10 \times 7.8 \mathrm{~mm}^{2}$ plates with a thickness of $1 \mathrm{~mm}$. The plates were heated to $875^{\circ} \mathrm{C}$ inside a carbon tube, held for $10 \mathrm{~min}$ and quenched in iced brine $\left(-19^{\circ} \mathrm{C}\right.$, quenching rate of $2700 \mathrm{~K} / \mathrm{s}$ measured with on-welded type $\mathrm{K}$ thermocouple) or quenching oil $\left(23{ }^{\circ} \mathrm{C}\right.$, quenching rate of $250 \mathrm{~K} / \mathrm{s}$ ). For microstructural analysis the samples were mounted in thermosetting resin with carbon as electrically conductive filler material $\left(185^{\circ} \mathrm{C}, 180 \mathrm{kN}\right.$ for $6 \mathrm{~min}$ ) and mechanically ground with $\mathrm{SiC}$ grinding paper (800, 1200 and 4000 grit) and polished (polycrystal diamond suspensions: 3 and $1 \mu \mathrm{m}$ ). As a last preparation step, vibration polishing with a $0.05 \mu \mathrm{m} \mathrm{SiO}$ suspension was employed. The polished samples were analyzed directly or subjected to two different etching processes for increasing the phase contrast. Either glow discharge (GD) plasma etching (600 V AC, $2 \mathrm{hPa}$, Argon 99.999 pct, anode diameter: $2.5 \mathrm{~mm}$, duration: 5 seconds $^{[19]}$ ) or a two-step chemical etching consisting of 6 seconds swirling in $10 \mathrm{wt}$ pet $\mathrm{NaOH}$ solution and subsequent $5 \mathrm{sec}-$ onds swirling in a solution of $120 \mathrm{~mL}$ distilled Water and $10 \mathrm{~g}$ ammonium tetrachlorocuprate(II) dihydrate were carried out. Optical microscopy with and without polarized light that allows the identification of martensite based on its birefringent properties. Differential interference contrast (DIC) method was used to analyze surface structures after etching. For measuring concentration profiles and analyzing the microstructure at higher magnifications, scanning electron microscopy (SEM) with backscattered electron detector (BSD), energy-dispersive X-ray spectroscopy (EDX), and electron backscatter diffraction analysis (EBSD) were employed.

\section{RESULTS}

The microstructure in the diffusion zone after the welding process is characterized by $\alpha$ and $\beta$ phases separated by a defined interface parallel to the initial welding contact plane. In the $\beta$ phase, the $\mathrm{Zn}$ concentration decreases towards the interface, while in the $\alpha$ phase the $\mathrm{Zn}$ concentration increases towards the interface. The concentration difference between the $\alpha$ and $\beta$ phase at the interface corresponds to the equilibrium solvus concentrations at $800{ }^{\circ} \mathrm{C}$, calculated using the software package Pandat ${ }^{\mathrm{TM}} 2018$ and the most recent description of the phase diagram from Liang and Schmidt-Fetzer. ${ }^{[20]}$ Al is uniformly distributed throughout the sample. After diffusion welding, the structure consists of large grains with a grain size in the $\alpha$ phase of $\sim 0.5 \mathrm{~mm}$ and in the $\beta$ phase of $\sim 1 \mathrm{~mm}$.

Microstructures of the diffusion couple $\mathrm{Cu}$ $30 \mathrm{Zn}-1.5 \mathrm{Al} / / \mathrm{Cu}-50 \mathrm{Zn}-1.5 \mathrm{Al}$ after quenching in iced brine are shown in Figure 1. After polishing (Figure 1(a)), the image contrast is weak, but the identification of $\alpha$ and $\beta$ phase is possible, while other phases are not visible. After the two-step chemical etching (Figure 1(b)), a phase selective chemical deposition of the reactants increases the contrast. The $\alpha$ phase appears in different shades of brown, depending on the orientation of the individual grains. The $\beta$ grains and $\beta$ precipitates that form in the $\alpha$ phase during the 10 minutes heat treatment prior to quenching are of uniform blue color. The assignment of $\alpha$ and $\beta$ was verified using EDX (Figure 2) and EBSD point analysis.

In the area in front of the former $\alpha / \beta$ interface within the former $\beta$ phase region, a different phase indicated by reddish-brown color can be seen (Figure 1(b)), it has a clear color contrast to the light brown of $\alpha$ and the blue of $\beta$. The phase is also clearly visible in the electron channeling contrast (ECC) in the BSD image in Figure 1(c). It has a plate-like morphology with distinct domain which is the typical martensite structure in $\mathrm{Cu}-\mathrm{Zn}-\mathrm{Al}$ alloys. ${ }^{[8-11]}$

The result of the EDX line scan in Figure 1(c) is shown in Figure 2. For the analysis, an accelerating voltage of $20 \mathrm{kV}$ (W cathode) and a step size of $8 \mu \mathrm{m}$ was used. The local composition of martensite is the same as that of the $\beta$ phase prior to quenching. After 10 minutes at $875{ }^{\circ} \mathrm{C}$, the concentrations of the $\alpha$ and $\beta$ phase at the interface are consistent with the calculated solvus concentrations at $875{ }^{\circ} \mathrm{C}$.

In polarized light (Figure 3(a)), details of the martensite microstructure become visible due to the anisotropy of the martensite crystal structure (birefringence). After grinding and polishing (without any etching), martensite appears bright and with high contrast compared to the $\alpha$ and $\beta$ phases. The color of individual crystal orientations changes depending on their position relative to the incidence angle of polarized light. One or two different crystal orientations of martensite plates are observed within the same $\beta$ parent grain. Considering the high transformation rates, the abrupt stop of martensite growth shows the high sensitivity of the martensite start 

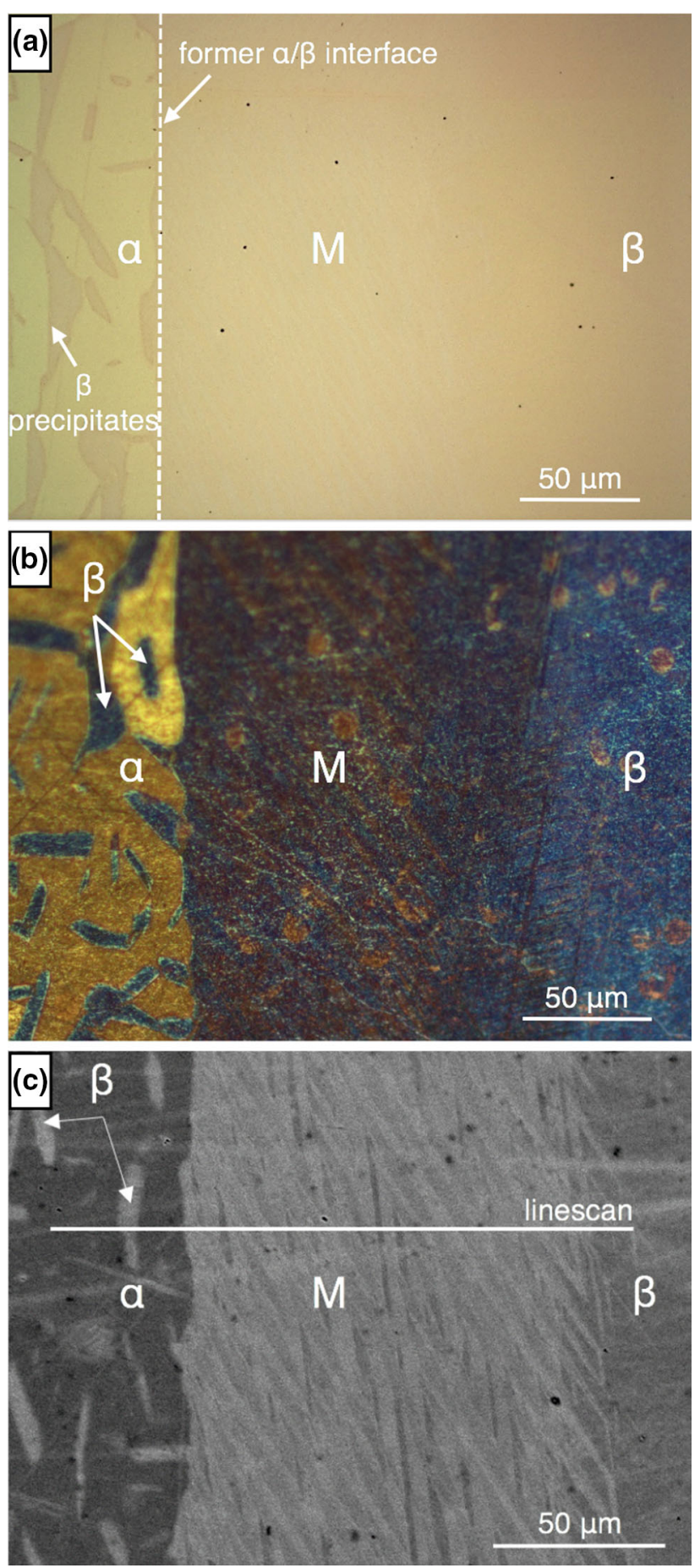

Fig. 1-Microstructures of the diffusion couple after quenching in iced brine; formation of martensite is not visible after polishing $(a)$ but can be clearly identified after the two-step chemical etching $(b)$ and in channeling contrast of BSD imaging $(c)$.

temperature on the composition. This effect becomes clearly visible in the graded samples. The formation of martensite is also observed in all $\beta$ precipitates that have similar concentration as the $\beta$ phase at the former $\alpha /$ $\beta$ interface.

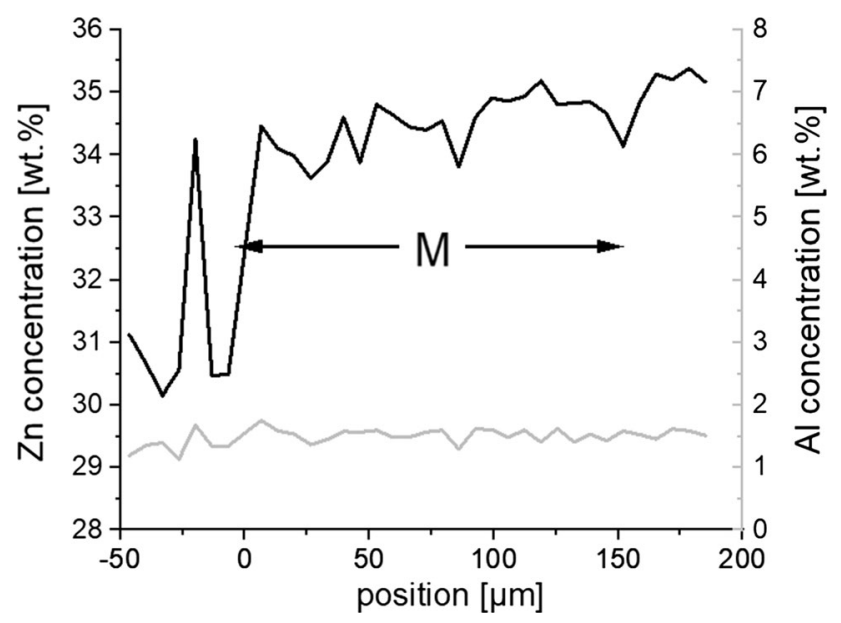

Fig. 2-Concentration profiles of $\mathrm{Zn}$ and $\mathrm{Al}$ after quenching in iced brine.
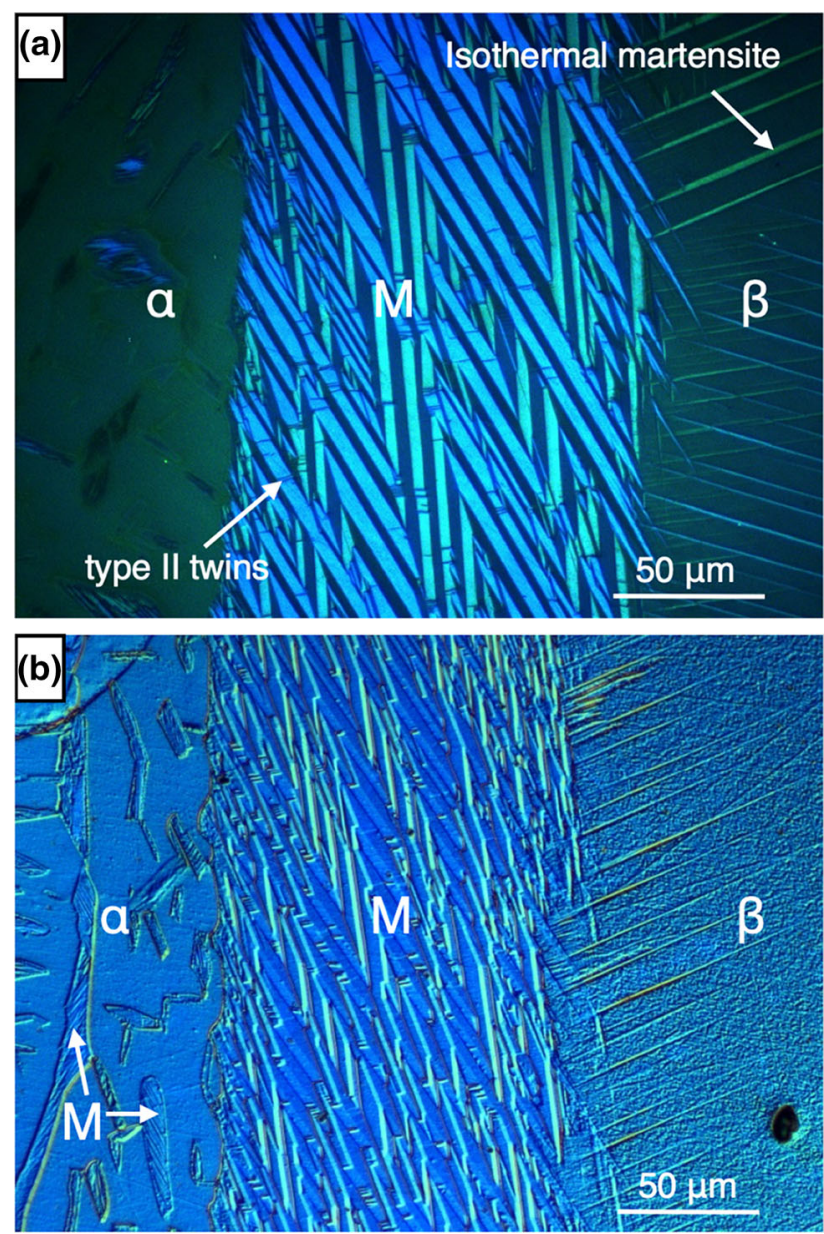

Fig. 3-Martensite plates under (a) polarized light after vibration polishing or $(b)$ optical differential interference contrast (DIC) after GD plasma etching.

The shape of martensite plates in Figure 3 is similar to that in commercial $\mathrm{Cu}-\mathrm{Zn}$-Al shape memory alloys ${ }^{[5]}$ which is commonly described as the self-accommodating martensite plate variant. ${ }^{[21]}$ This martensite variant is associated with a $18 \mathrm{R}$ structure and type II twinning. ${ }^{[1]}$ 
In comparison with typical $\mathrm{Cu}$-based shape memory alloys, ${ }^{[11]}$ the twin density in Figure 3 is significantly lower. Thus, the composition range investigated here is not promising for SMAs.

In the single $\beta$ phase region at higher $\mathrm{Zn}$ concentrations ( $>150 \mu \mathrm{m}$ distance from the former $\alpha / \beta$ interface), in addition to the martensite grown during quenching, isothermally grown thermoelastic martensite is observed. One possible reason for the occurrence of isothermal martensite is the formation of oxides on the sample surface that changes the solute concentration and the martensite start temperature locally, leading to the growth of the second type of martensite at the surface. ${ }^{[2,23]}$ The phase fraction of the isothermal martensite increases with time. It can be temporally removed by grinding, but reappears after a day in air at room temperature.

After GD plasma etching (Figure 3(b)), the sample surface is contrasted due to the phase and crystal orientation dependent erosion rate. In optical differential interference contrast (DIC), the $\alpha, \beta$, and martensite phases are visible without any chemical etching. Within individual crystals, twin boundaries are observed (see also Figure 3(a)).
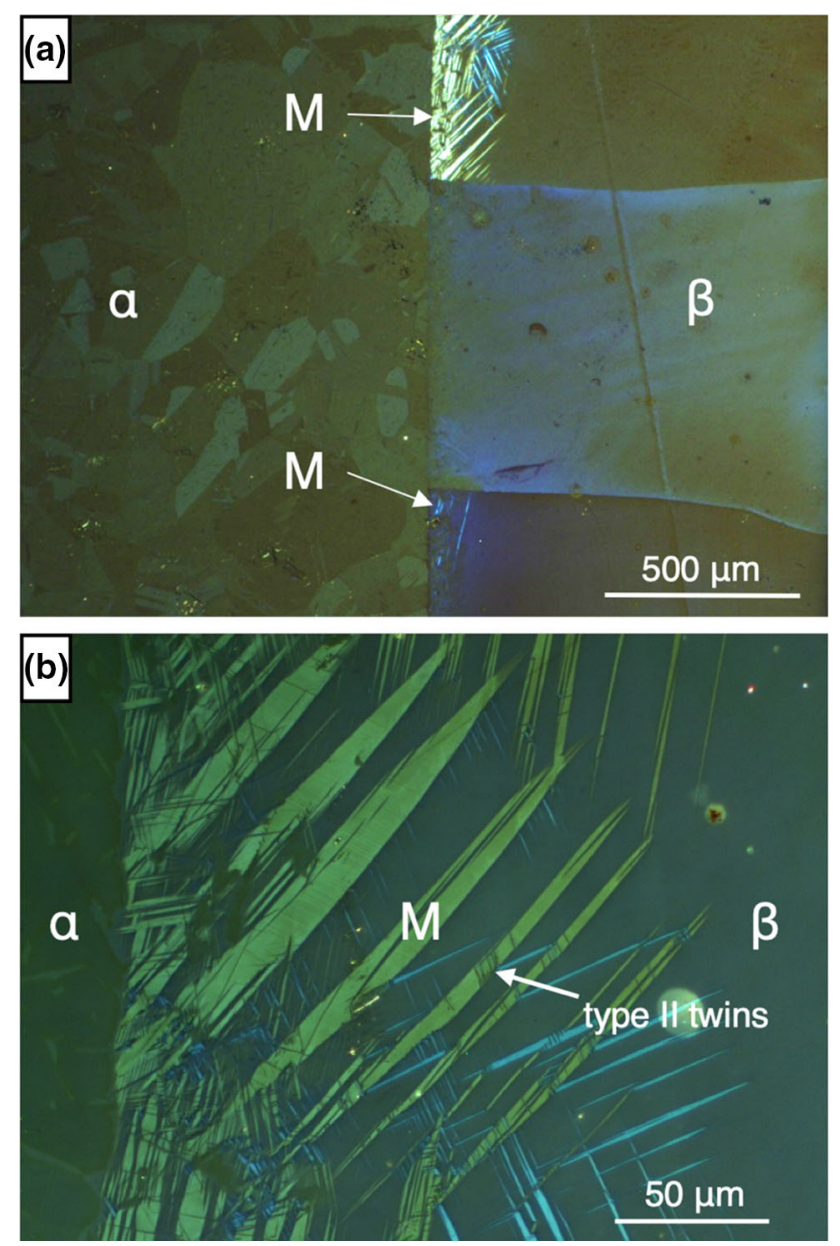

Fig. 4-Lenticular shaped plate martensite after quenching in oil, observed after polishing in polarized light at $(a)$ low and $(b)$ high magnification.
Figure 4 shows the microstructure of the same sample as in Figure 3 (i.e. identical local solute concentration distribution and heat treatment before quenching) after quenching in oil, not iced brine. Applying lower a cooling rate $(250 \mathrm{~K} / \mathrm{s}$ instead of $2700 \mathrm{~K} / \mathrm{s})$, martensite forms no longer uniformly along the entire $\alpha / \beta$ interface, but occurs only in some grains, often in form of small clusters. The phase fraction of martensite is lower after quenching with lower cooling rates and the shape of martensite changes from thin to lenticular shaped plates. The martensite plates in Figure 3(a) have a width of $\sim 4 \mu \mathrm{m}$ and a distance of $\sim 3.4 \mu \mathrm{m}$ between each other. At lower rates, the martensite in Figure 4(b) is much coarser. The width of the lentils is $\sim 5.5 \mu \mathrm{m}$ and the distance between individual lentils is $\sim 11.5 \mu \mathrm{m}$.

Martensite lentils have been observed in other alloy systems, e.g., steels, ${ }^{[12]}$ and are typically associated with a fully twinned midrib region and a neighboring untwinned region that extents to the lentil/matrix phase boundary. This substructure is not observed here, but only the formation of twins from one lentil/matrix phase boundary to the other. To the authors best knowledge, this is the first time that martensite with lenticular morphology has been observed in $\mathrm{Cu}$ alloys.

During quenching of $\mathrm{Cu}-\mathrm{Zn}-\mathrm{Al}$ alloys, the observed type of martensite is reported to depend on the parent phase. $9 \mathrm{R}$ is formed from ordered $\beta^{\prime}$ and $18 \mathrm{R}$ from disordered $\beta .^{[5,8,9]} 9 \mathrm{R}$ and $18 \mathrm{R}$ are different polytypes with quite similar crystal structure. The crystal structure of $18 \mathrm{R}$ equals that of $9 \mathrm{R}$ except for doubling of the unit cell along the b-axis and c-axis directions. It is also known that 9R can exclusively form from $\beta^{\prime} .^{[24]}$ In the present study, EBSD analysis was employed to identify the martensite type for the two observed morphologies, particularly self-accommodating thin plate martensite (Figure 3) and lenticular shaped plate martensite (Figure 4). In the CIF format, the polytypes were created based on a P1 triclinic crystal structure using the lattice parameter of $\mathrm{Cu}-\mathrm{Zn}$ with 50 at petZn from Reference 25, which was converted to the corresponding lattice parameter of the respective polytypes. If martensite has a monoclinic angle smaller than $90 \mathrm{deg}$, it is called "modified" martensite and the "normal" polytype 9R (or 18R) becomes M-9R (or M-18R). ${ }^{[26]}$ In the present paper, the monoclinic distortion was varied using a distortion factor as defined in Reference 24 The Kikuchi pattern for 9R, 18R, M-9R, and M-18R were simulated dynamically using the Bruker ESPRIT DynamicS software. For the self-accommodating thin plate martensite (Figure 3) and the lenticular shaped plate martensite (Figure 4), the Kikuchi patterns were found to be identical. By far the best match between simulated and measured Kikuchi patterns was observed for "normal" (undistorted) martensite. Since the monoclinic distortion is directly related to long-range ordering in the parent phase, the experimental findings strongly indicate the formation of both martensite morphologies from disordered $\beta$ phase during quenching from $875^{\circ} \mathrm{C}$, resulting in $18 \mathrm{R}$ crystal structure. ${ }^{[27]}$

All previous results are from samples with $1.5 \mathrm{wt}$ pct Al. With decreasing Al concentration, the martensitic transformation is in competition with massive 
transformation, as shown in Figure 5. After quenching of samples with identical dimensions in iced brine, for Al concentrations $\leq 0.5 \mathrm{wt}$ pct only massive transformation (Figure 5(a)), between 0.5 and 1.5 wt pct Al martensitic and massive transformation (Figure 5(b)) and $\geq 1.5 \mathrm{wt}$ pct Al only martensitic transformation (Figure $5(\mathrm{c})$ ) are observed in the $\beta$ phase in front of the former $\alpha / \beta$ interface. The different microstructures in Figure 5 show
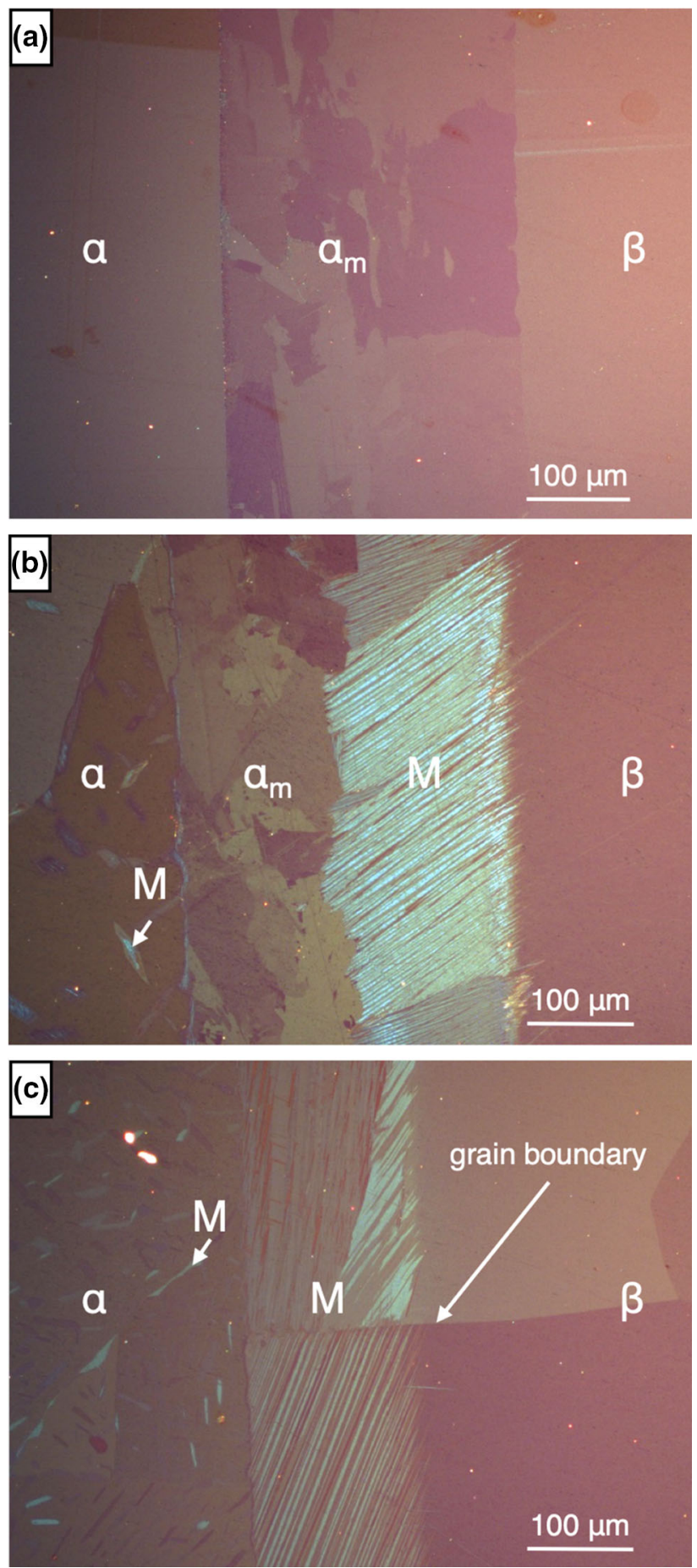

Fig. 5-Martensite "M" and/or $\alpha$ phase from massive transformation " $\alpha_{\mathrm{m}}$ " depending on the $\mathrm{Al}$ concentration; $0.5 \mathrm{wt}$ pet $\mathrm{Al}$ in $(a), 0.75$ wt pet $\mathrm{Al}$ in $(b)$ and 1.5 wt pet $\mathrm{Al}$ in $(c)$. how massive or martensitic transformation compete at quenching rates high enough to prevent solute partitioning.

\section{DISCUSSION}

The experiments described in this work were successful in creating samples with defined $\mathrm{Zn}$ concentration profiles, allowing to study a range of compositions within a single experiment. The phase identification in graded samples is challenging since several stable and/or metastable phases are present. The introduced two-step selective color etching for light microscopy allows the correlation of colors to phases over the entire concentration range. Exploiting the birefringence properties of the martensitic phase, self-accommodating thin plate (Figure 3(a)) and lentil martensite (Figure 4(b)) were distinguished from other phases without any chemical etching, minimizing the experimental effort for phase analysis. The birefringence contrast and thus the image quality are sensitive to the surface quality after metallographic preparation. Employing vibration polishing as final step, details within the martensitic phase, e.g., the twin density, becomes visible. The combination of the presented preparation methods offers the possibility to systematically scan the system for suitable concentrations for different types of phase transformations and potential applications as, e.g., shape memory alloys.

The martensite morphology changes significantly with the cooling rate. At lower rates, the martensite plates are coarser and lenticularly shaped. Martensite is no longer found along the entire former $\alpha / \beta$ interface, but appears only locally. It is assumed that the lower cooling rate leads to the formation of martensite at lower undercoolings with lower nucleation rate. The stress in the matrix around the needles prevents the nucleation of further martensite with increasing undercooling, and the existing martensite grows in lateral direction, which leads to a coarser microstructure.

Both concentration invariant transformations, particularly martensitic and massive, can occur in the same concentration range. For martensitic transformation, a higher cooling rate is necessary. The transformation causes strong internal stresses that require further driving force (higher undercoolings), so that the transformation occurs considerably below the partitionless transformation temperature ( $\mathrm{T}_{0}$ temperature). Massive transformation involves diffusion in the interfacial region and is thermodynamically possible just below the $\mathrm{T}_{0}$ temperature. Due to the fast diffusion of $\mathrm{Zn}$ in $\mathrm{Cu}$, massive transformation was found experimentally to start at the solvus temperature $\alpha+\beta$ in $\alpha^{[28]}$ In Table I, the calculated martensite start temperatures using Reference 15 and the solvus temperatures $\alpha+$ $\beta$ in $\alpha$ for the respective concentrations, calculated using the thermodynamic data in Reference 20 are given. In the entire concentration range, the solvus temperature is significantly higher than the martensite start temperature, i.e., massive transformation should be present in all cases, but is only observed in the samples with $0.5 \mathrm{wt}$ pet Al (Figure 5(a)) and 0.75 wt pet Al (Figure 5(b)). 
Table I. Composition Range of the Concentration Invariant Reactions, Solvus Temperature as Start Temperature for Massive Transformation in $\mathrm{Cu}-\mathrm{Zn}^{[28]}$ and Martensite Start Temperature in Cu-Zn-Al Calculated Using the Empirical Relation of Ref. [15] that Is Valid for Al Concentrations $<3$ at. pet ( 2.35 wt pet)

Compositional Range

Solvus Temperature $\alpha+\beta$ in $\alpha$

Martensite Start Temperature

0.5 Wt Pct Al, 36-38 Wt Pct Zn, Cu Bal.

0.75 Wt Pet Al, 35-36.5 Wt Pet Zn, Cu Bal.

430 to $550{ }^{\circ} \mathrm{C}$

450 to $550{ }^{\circ} \mathrm{C}$

1.5 Wt Pct Al, 34-36 Wt Pet Zn, Cu Bal.

530 to $720^{\circ} \mathrm{C}$

-87 to $70^{\circ} \mathrm{C}$

-24 to $94^{\circ} \mathrm{C}$

-145 to $9{ }^{\circ} \mathrm{C}$

The sample with $1.5 \mathrm{wt}$ pct $\mathrm{Al}$ has the largest difference between the calculated solvus temperature and the martensite start temperature. However, experimentally only the formation of martensite is observed (Figure 5(c)). The quenching rates are the same for all samples. Consequently, the absence of massive transformation in the sample with $1.5 \mathrm{wt}$ pct $\mathrm{Al}$ (that theoretically allows massive transformation in the largest temperature interval) is not a nucleation problem. In $\mathrm{Fe}-\mathrm{C}$, an influence of the grain size on the formation of martensite is reported in the literature. Larger parent phase grains result in an increase of the martensite start temperature $M_{\mathrm{s}}{ }^{[28,29]}$ For example, a grain size increase from 35 to $50 \mu \mathrm{m}$ causes an increase in $M_{\mathrm{s}}$ of $15 \mathrm{~K}^{[28]}$ In the present case, the time at elevated temperatures for diffusion welding results in even much larger grains (in the order of $1 \mathrm{~mm}$ ). However, the martensite start temperature will not increase with grain size without limit, so that there is still sufficient undercooling for the transformation. This and the fact that massive transformation occurs in the other samples that have the same grain size shows that there is only a minor influence of the grain size on the transformations in the present case. In a previous publication, ${ }^{[18]}$ the present authors investigated the influence of $\mathrm{Al}$ on the rate of massive transformation in binary $\mathrm{Cu}-\mathrm{Zn}$. With increasing $\mathrm{Al}$ concentration, a decrease of the massive transformation rate was observed. Considering the presence of solute fluxes in the interfacial region, a possible reason is the more complex diffusion in multicomponent system that influences the selection of tie-lines and reduces the driving force for interface migration. Apparently, the massive transformation rate decreases with increasing Al content, until only the formation of martensite is observed.

\section{CONCLUSIONS}

Employing different sample preparation techniques for optical microscopy, the various phases appearing in quenched $\mathrm{Cu}-\mathrm{Zn}-\mathrm{Al}$ alloys are identified fast and reliably. Details of the martensitic microstructure are also visible. The martensite morphology in $\mathrm{Cu}-\mathrm{Zn}-\mathrm{Al}$ alloys is found to change depending on the cooling rate, a feature that has been documented in other alloy systems, but so far not in $\mathrm{Cu}-\mathrm{Zn}$ alloys. After quenching in iced brine $\left(-19^{\circ} \mathrm{C}\right)$, self-accommodating thin martensite plates with type II twins are observed; after quenching in oil $\left(23^{\circ} \mathrm{C}\right)$, coarse lenticular shaped martensite plates form while the polytype seems to remain the same, $18 \mathrm{R}$. In the graded samples, the competition between martensitic and massive transformation is accessible in a unique way. The addition of $\mathrm{Al}$ decreases the massive transformation rate to such an extent that despite the fact that the $\alpha+\beta / \alpha$ solvus temperatures for all concentrations are significantly higher than the martensite start temperatures, only the formation of martensite is observed at $\mathrm{Al}$ concentration higher than $1.5 \mathrm{wt}$ pct.

\section{ACKNOWLEDGMENTS}

Open Access funding provided by Projekt DEAL. The EBSD measurements and analysis were carried out at the TU Bergakademie Freiberg, Germany. The authors are grateful to the members of the Institute of Materials Science for their support, especially for the discussion that helped clarifying the structure of the two martensite morphologies. In particular, the authors want to mention the help of Alexander Walnsch and Peter D.B. Fischer. Furthermore, the authors gratefully acknowledge financial support of the Deutsche Forschungsgemeinschaft (DFG) under Grant No. LI 2827/1-1.

\section{OPEN ACCESS}

This article is licensed under a Creative Commons Attribution 4.0 International License, which permits use, sharing, adaptation, distribution and reproduction in any medium or format, as long as you give appropriate credit to the original author(s) and the source, provide a link to the Creative Commons licence, and indicate if changes were made. The images or other third party material in this article are included in the article's Creative Commons licence, unless indicated otherwise in a credit line to the material. If material is not included in the article's Creative Commons licence and your intended use is not permitted by statutory regulation or exceeds the permitted use, you will need to obtain permission directly from the copyright holder. To view a copy of this licence, visit http://creat ivecommons.org/licenses/by $/ 4.0 /$.

\section{REFERENCES}

1. A.J. Philips: Trans. Metall. Soc. AIME, 1930, vol. 89, pp. 194-200.

2. J.W. Cahn, M. Cohen, and D.A. Karlyn: Trans. Metall. Soc. AIME, 1969, vol. 245, pp. 197-207.

3. T.B. Massalski: Metall. Mater. Trans. A, 2002, vol. 33A, pp. 2277-83. 
4. V. Asanović, K. Delijić, and N. Jauković: Scr. Mater., 2008, vol. 58 , pp. 599-601.

5. T. Saburi and C.M. Wayman: Acta Metall., 1979, vol. 27, pp. $979-95$.

6. M.A. Jaswon and J.A. Wheeler: Acta Crystallogr., 1948, vol. 1, pp. 216-24

7. E.R. Petty: Martensite: Fundamentals and Technology, Longman, Harlow, GB-ESS, 1970, pp. 101-02.

8. M. Ahlers: Prog. Mater. Sci., 1986, vol. 30, pp. 135-86.

9. R. Zengin and N. Kayal: Acta Phys. Pol. A, 2010, vol. 118, pp. 619-22.

10. Z. Stošić, D. Manasijevi, L. Balanovi, T. Holjevac-Grguri, U. Stamenkovi, M. Premovi, D. Mini, M. Gorgievski, and R. Todorovi: Mater. Res., 2017, vol. 20, pp. 1425-31.

11. K. Adachi, J. Perkins, and C.M. Wayman: Acta Metall., 1986, vol. 34 , pp. $2471-85$.

12. T. Maki: Phase Transform. Steels, 2012, vol. 2, pp. 34-58.

13. K. Bhattacharya: Arch. Ration. Mech. Anal., 1992, vol. 120, pp. 201-44.

14. M.J. Perricone: Book Chapter: Massive Transformation Structures in ASM Handbook Metallography and Microstructures 9, ASM International, Materials Park, OH, 2004, pp. 148-51.

15. H. Pops and T.B. Massalski: Trans. Metall. Soc. AIME, 1964, vol. 230 , pp. $1662-68$

16. R. Dasgupta: J. Mater. Res., 2014, vol. 29, pp. 1681-98.

17. W. Huang: Mater. Des., 2002, vol. 23, pp. 11-19.
18. S. Lippmann, T. Kaaden, P. Wutzler, and M. Rettenmayr: $M a-$ terialia, 2019, vol. 7 (100367), pp. 1-7.

19. A. Undisz, K.E. Freiberg, A. Seide, T. Koenen, and M. Rettenmayr: Prakt. Metallogr., 2016, vol. 53, pp. 86-97.

20. S.M. Liang and R. Schmid-Fetzer: CALPHAD, 2016, vol. 52, pp. 21-37.

21. E. Hornbogen and H. Warlimont: Metalle - Struktur und Eigenschaften der Metalle und Legierungen, 6th ed., Springer Vieweg, Berlin, 2016, p. 193.

22. D.Z. Yang, M. Zhu, M. Qi, and G.B. Li: Scr. Metall., 1986, vol. 20, pp. 1717-20.

23. F.C. Lovey, J. Ferron, L.S. De Bernardez, and M. Ahlers: Scr. Metall., 1983, vol. 17, pp. 501-04.

24. E.-S. Lee and S. Ahn: Acta Mater., 1998, vol. 46, pp. 4357-68.

25. L.H. Beck, C.S. Smith: Trans. Amer. Inst. Mining, Metall. Petroleum Eng., 1952, vol. 194, pp. 1079-83.

26. S. Chakravorty and C.M. Wayman: Acta Metall., 1977, vol. 25, pp. $989-1000$.

27. D.W. Roh, E.-S. Lee, and Y.G. Kim: Metall. Trans., 1992, vol. 23A, pp. 2753-60.

28. D.N. Adnyana: Metallography, 1986, vol. 19, pp. 187-96.

29. J. Wu, B. Jiang, and T.Y. Hsu: Acta Metall., 1988, vol. 36, pp. $1521-26$.

Publisher's Note Springer Nature remains neutral with regard to jurisdictional claims in published maps and institutional affiliations. 